\title{
Case study of virtual reality in CNC machine tool exhibition
}

\author{
Yung-Chou Kao ${ }^{1, *}$, Chung-Shuo Lee ${ }^{2}$, Zhi-Ren $\mathrm{Liu}^{3}$, and $Y u-F u \mathrm{Lin}^{4}$ \\ ${ }^{1}$ Advanced Institute of Manufacturing with High-tech Innovations, National Chung Cheng University, No.168, Sec. 1, University Rd., \\ Min-Hsiung Township, Chia-Yi County 621, Taiwan (R.O.C.) \\ ${ }^{2}$ Advanced ${ }^{\text {Institute }}$ of Manufacturing with High-tech Innovations, National Chung Cheng University, No.168, Sec. 1, University Rd., \\ Min-Hsiung Township, Chia-Yi County 621, Taiwan (R.O.C.) \\ ${ }^{3}$ Department of Mechanical Engineering, National Chung Cheng University, No.168, Sec. 1, University Rd., Min-Hsiung Township, \\ Chia-Yi ${ }^{\text {County }} 621$, Taiwan (R.O.C.) \\ ${ }^{4}$ Micro/Meso ${ }^{\text {Mechanical }}$ Manufacturing R\&D Department, Metal Industry Research and Development Center, 1001 Kaonan Highway, \\ Kaohsiung, Taiwan 811 (R.O.C.)
}

\begin{abstract}
Exhibition and demonstration are generally used in the promotion and sale-assistance of manufactured products. However, the transportation cost of the real goods from the vender factory to the exposition venue is generally expensive for huge and heavy commodity. With the advancement of computing, graphics, mobile apps, and mobile hardware the 3D visibility technology is getting more and more popular to be adopted in visual-assisted communication such as amusement games. Virtual reality (VR) technology has therefore being paid great attention in emulating expensive small and/or huge and heavy equipment. Virtual reality can be characterized as 3D extension with Immersion, Interaction and Imagination. This paper was then be focused on the study of virtual reality in the assistance of $\mathrm{CNC}$ machine tool demonstration and exhibition. A commercial CNC machine tool was used in this study to illustrate the effectiveness and usability of using virtual reality for an exhibition. The adopted CNC machine tool is a large and heavy mill-turn machine with the width up to eleven meters and weighted about 35 tons. A head-mounted display (HMD) was attached to the developed VR CNC machine tool for the immersion viewing. A user can see around the 3D scene of the large mill-turn machine and the operation of the virtual CNC machine can be actuated by bare hand. Coolant was added to demonstrate more realistic operation while collision detection function was also added to remind the operator. The developed VR demonstration system has been presented in the 2017 Taipei International Machine Tool Show (TIMTOS 2017). This case study has shown that young engineers and/or students are very impressed by the VR-based demonstration while elder persons could not adapt themselves easily to the VR-based scene because of eyesight issues. However, virtual reality has successfully being adopted and integrated with the CNC machine tool in an international show. Another machine tool on laser-assisted milling machine motion simulation has also been successfully conducted to show the expandability of the VR based technology. One can conclude that VR will be adopted and paid more and more attention in the future in helping CNC machine tool promotion. Further study could be extended to education and training system, and also for the maintenance system, too.
\end{abstract}

\section{Introduction}

In response to the needs of small-volume/large-variation of products nowadays, the processing applications have a lot of customization requirements. The mechanical equipment manufacturers and the processing application engineers usually need to spend a lot of times in the communications and repeated changes to determine which equipment is the most suitable for customers. There are many factors need to be considered such as processing methods, product size, and other special needs, to name only a few. For the equipment manufacturers, how to demonstrate the characteristics of the device and to satisfy the needs of the customers is an important factor in determining the customer's motivation to buy.
So far, a variety of international machine tool exhibition, like EMO in Hannover, Germany, JIMTOF in Tokyo, Japan, IMTS in Chicago, United States of America, CIMT in Beijing, China, TIMTOS in Taipei, Taiwan, etc. have been held regularly. When a region held an international machine tool exhibition, the nearby machinery and equipment manufacturers will generally gather together and show in the exhibition their equipment characteristics and advantages, but are limited by the space of the site and the booth. Therefore, the machine tools that can be moved to the exhibition hall are limited. So the equipment manufacturers will be subjected to this limitation when negotiating with their potential customers. They can only provide with the specifications of a series of products or a similar

* Corresponding author: imeyckao@,ccu.edu.tw 
machine tool in the exhibition hall. Another limitation is the cost of the transportation, the equipment manufacturers of huge machinery such as the heavy lathe will spend more cost on transportation by freighter, also on assembling, disassembling and labour cost. It will cost more than other lighter machine tools.

In order to attract more customers, the manufacturers will exhibit the best product and technology of the year. There are often three ways of demonstrations.The first is showing the technology by operating the machine tool in the exhibition, but it is expensive. The second is using videos or other digital technology to present the new functions of the machine, but it has the disadvantage that the customers cannot experience the product clearly. The third is the most conventional way to present the machined product by the machine tool, the customers can only understand the machine tool by catalogue, and the customers cannot view the real motion of the machine tool.

With the advancement of computer graphics, 3D visualization technology is getting more and more inexpensive and popular [1,2]. Amer and Peralez used low cost material and smart phone to make the VR Head-mounted Display (HMD) [1]. Zielinski et al. [2] developed the $3 \mathrm{D}$ visualization by using the Oculus Rift SDK and using MATLAB to transform 2D desktop display to $3 \mathrm{D}$ display in VR robotics collaboration. Besides the application of the virtual reality in games, applications have also been gradually introduced to research and development of other industries [3], e.g., the equipment manufacturing exhibition of 3D interactive media [4], motion of machine tool [5], machine tool-aided design [6], home design [7], smart manufacturing [8], robotic arm dynamic and simulation [9], creating new museum experiences [10], reducing work accidents [11] and education [12,13,14,15]. In the application to education, the user experience has been studied [12]. With the development of VR technology, it has been used for industry skills training[13], and for virtual vehicle and virtual production in automotive engineering education [14]. The 3D virtual reality experiments have been developed for circuit experiments in the electrical engineering education [15].

Therefore, this paper aims for enhancing the communication between customers and machine tool makers through the development of a demonstrationassisted virtual reality software with case study to ease realization. Exhibitors and Salesman can make a strong first impression with customers, and convert the 2D catalogue to interactive $3 \mathrm{D}$ experience. In order to make the virtual environment to real world, the customers can touch virtual panel to control the virtual machine tool by sensor of hand motions. Besides the motion simulation, the function of input $\mathrm{NC}$ programs and detection of collision are also developed. Using virtual reality technology on the demonstration could avoid the transportation of heavy machine tool to the exhibition for reducing the cost, it also could let customers view the machine tool from different angles.

\section{System structure}

The 3D model of a huge mill-turn VR machine tool is shown in Figure 1 with its width 11 meters. Figure 2 is the kinematic chain of the machine tool. In this kinematic chain, $\mathrm{O}$ is the starting origin, $\mathrm{O} *$ indicates that there is no relative motion with $\mathrm{O}$. $\mathrm{C}$ represents the rotation axis in $\mathrm{C}$-axis, $\mathrm{W}$ means workpiece, $\mathrm{Z}$ represents the linear axis in the $\mathrm{Z}$-axis direction, $\mathrm{X}$ represents the linear axis in the $\mathrm{X}$-axis direction, $\mathrm{B}$ represents the rotation axis in B-axis, $\mathrm{Y}$ represents the linear axis in the $\mathrm{Y}$-axis direction, $\mathrm{S}$ represents the rotation axis in subspindle, $\mathrm{T}$ represents the rotation axis in tool, $\mathrm{T}^{*}$ represents the tip of tool and there is no relative motion relationship with $\mathrm{T}$.

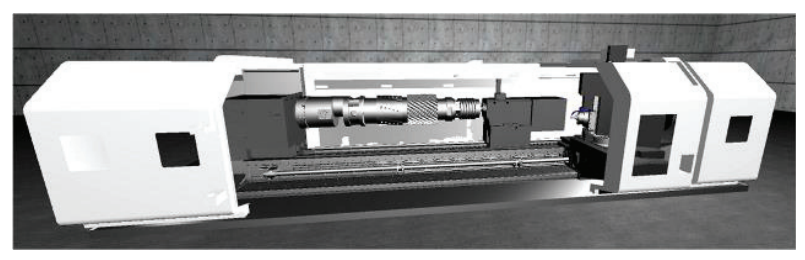

Fig 1. 3D model of the VR mill-turn machine tool.

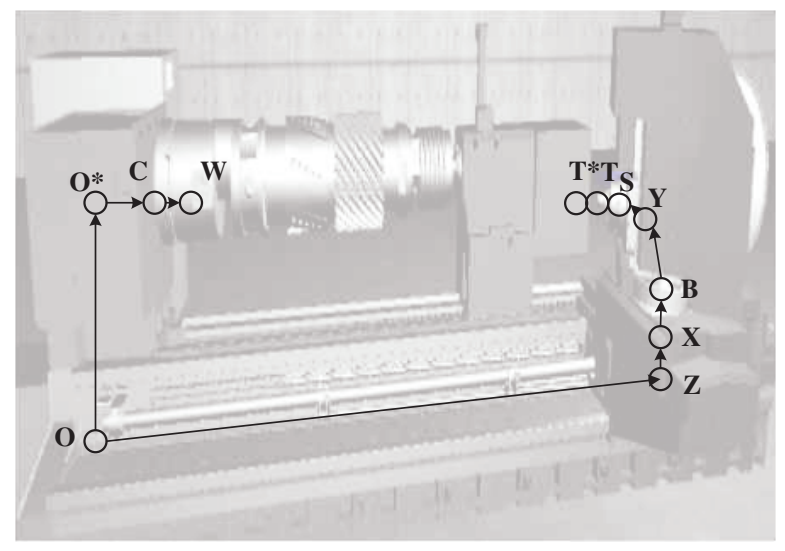

Fig 2. Kinematic chain of the developed VR mill-turn machine.

In VR machine tool, in order to simulate the machine movement during the operation, both the Virtual and/or Real CNC Controllers can be employed to read the NC code. The controller can interpret the NC code into motion information of each axis and then sends the information to the VR Client program. The VR Client is connected to the VR Server of the VR Machine Tool by sending the information to the Virtual Controller. After that, the Virtual Controller issues commands to move the Machine Tool Model. The system structure of the proposed VR Machine Tool is shown in Figure 3. 
VR Machine Tool

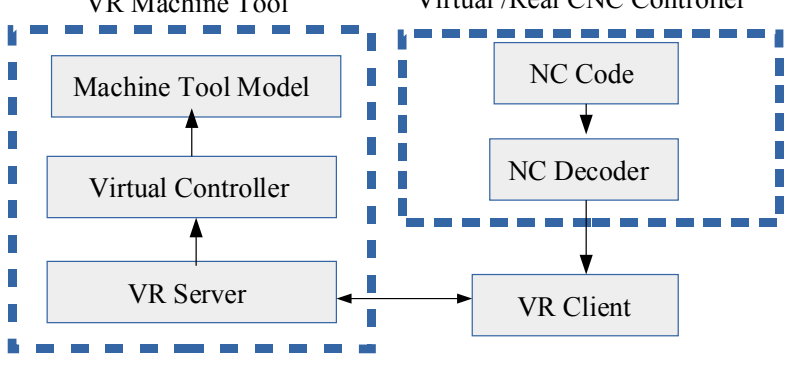

Fig 3. System Structure of the proposed VR machine tool.

\section{System implementation}

To build a VR machine tool, the 3D model of the machine tool was first constructed with a CAD system, according to the kinematic model of the machine tool. The machine components were split into two groups: movable compoments and fixed compoments. Then, the compoments were classified by functions, for the millturn machine tool. There are the sheet metal parts, the base, the various moving linear axes, the rotation axes, the tailstock, the turret, and so on. The 3D model files of each component were exported and converted into the formats that were supported by the Unity $3 \mathrm{D}^{\mathrm{TM}} \mathrm{VR}$ development environment.

After imported the 3D model file to VR development environment, according to the heirachical structure of the VR machine tool motion (as shown in Figure 4.) to establish the linkage of the various components for the machine motion, the motion functions were programmed in $\mathrm{C} \#$ scripts. Then, a Virtual Controller was developed with a program allowing for the user to operate the VR Machine Tool.

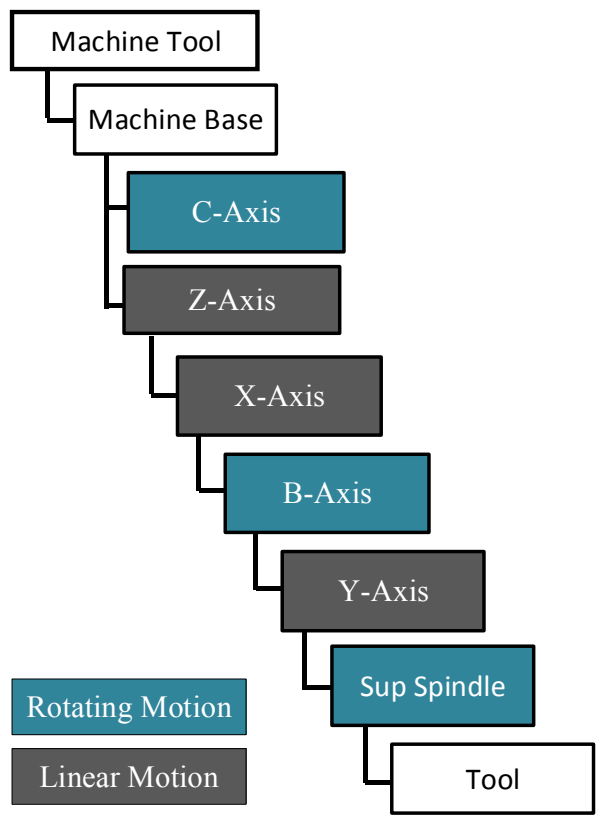

Fig 4. Heirachical structure of the VR machine tool motion.
To make the VR machine tool motions more authentic, a collision detection fuction was added. This is accomplished by adding a collision-check object outside the $3 \mathrm{D}$ model, the object can be represented by rectangle, sphere, cylindr or in accordance with the mesh of 3D model. It would be most accurate by using the mesh geometry of 3D model to determine the collision, but the computational loading is also much heavier and costly. This loading could be lessened by using simple parts as bounding boxes, i.e. rectangle, sphere or cylinder, can greatly improve the efficiency and improve performance in collision check. In the VR machine tool, the color of the collided compoment will be changed to red and a warning audio will be played to remind the user when the collision is detected.The collision detection examples are shown in Figure 5.

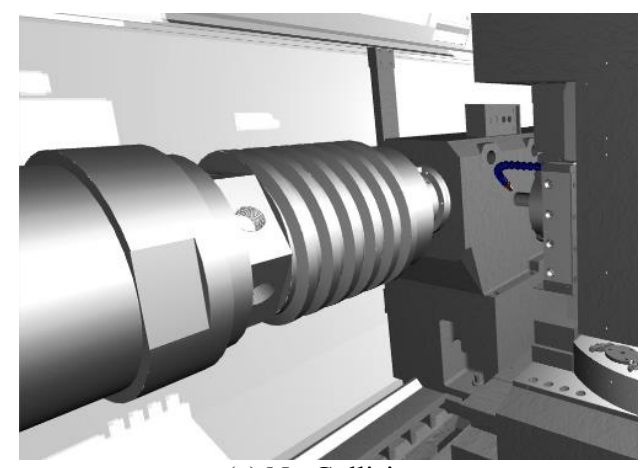

(a) No Collision.

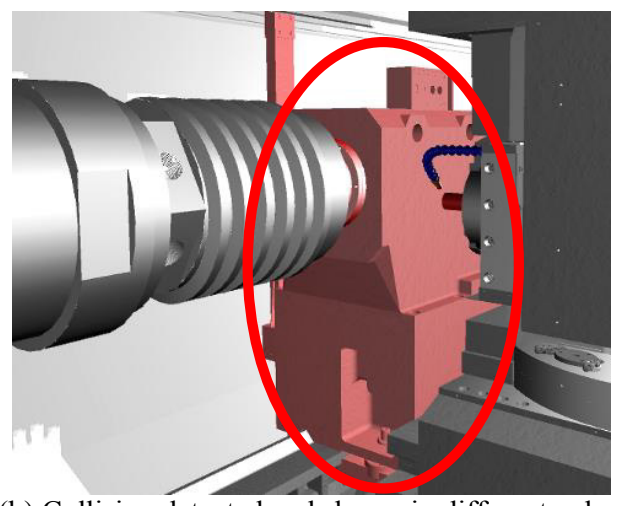

(b) Collision detected and shown in different color. Fig 5. Examples for collision detection..

In order to allow for the users to have more realistic experences when operating the machine tool, a gesture sensor was applied outside the VR HMD, thus the user's gestures were grabbed for controlling the control panel, as shown in Figure 6.

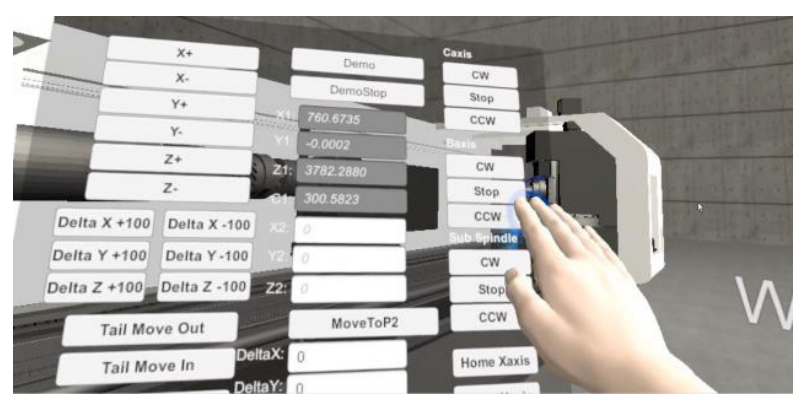

Fig 6. Using hand to touch the control panel. 
In the control panel, it can be divided into 3 parts accroding to $\mathrm{NC}$ code functions:

(1) Related to G code: Mechine coordinates display, Movement by incremental coordinates, Movement by absolute coordinates, Origin return of axes, Rotation angle of rotary axes.

(2) Related to M code: Clockwise and couter clockwise of spindles, Automatic tool change, Coolant spay.

(3) Others: Tailstock movement, Network connection for real and virtual controllers.

The user's viewing angle can be changed by using the develoepd VR controller, as shown in Figure 7.

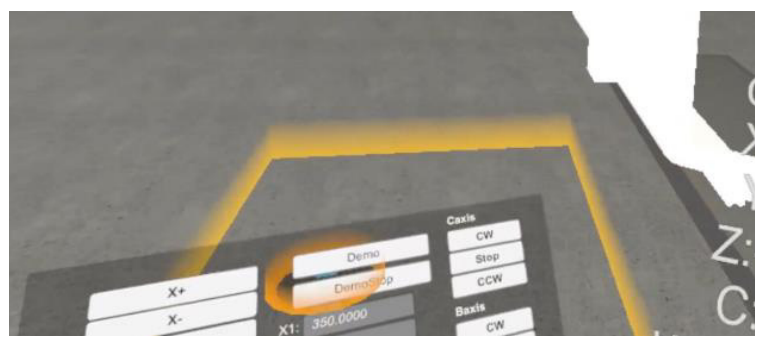

Fig 7. Move in scene to change the viewing angle.

Furthermore, in order to be more realistic, the coolant function was added to the simulation. Figure 8 shows the scene with spraying coolant.

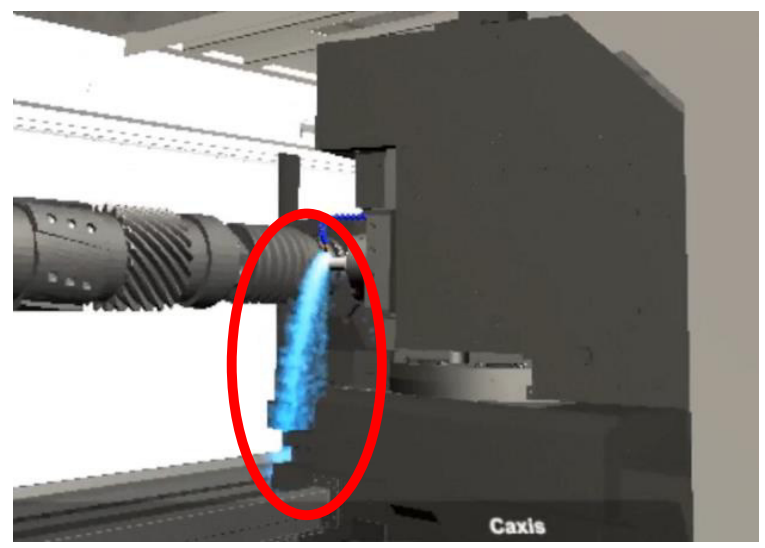

Fig 8. The coolant spray display.

\section{Results and discussions}

The developed VR demonstration system has been presented in the 2017 Taipei International Machine Tool Show (TIMTOS 2017), as shown in Figure 9. Figure 10 shows the screen seen by the user when the VR machine tool simulates the machine tool.

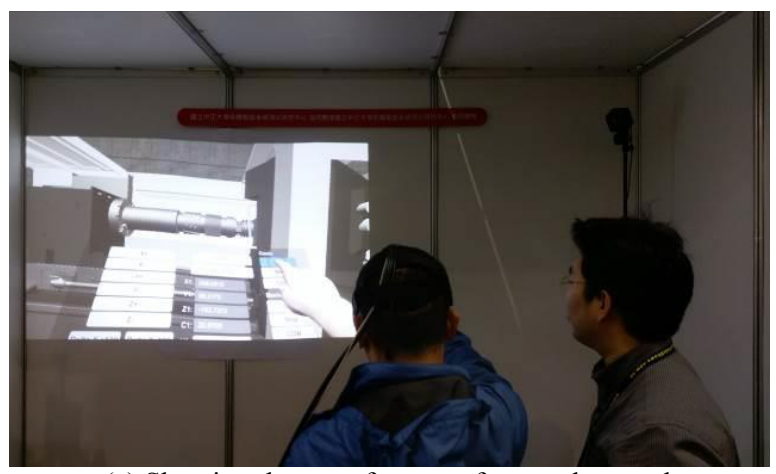

(a) Showing the use of gesture for panel control

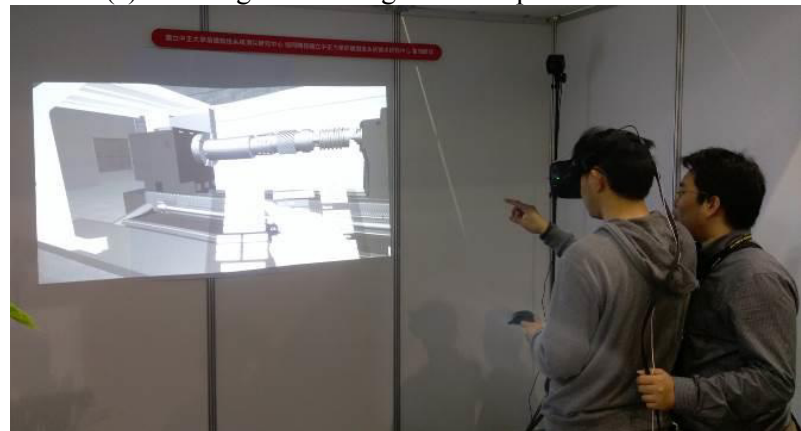

(b) Showing the use of 3D helmet for viewing the machine

Fig 9. System demonstration at TIMTOS 2017.

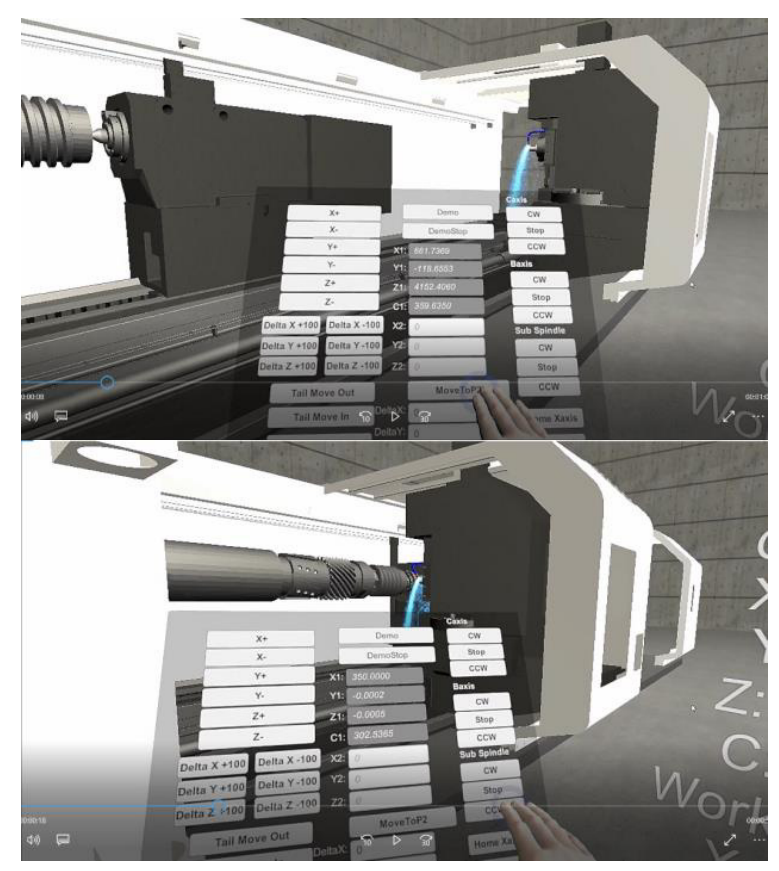

Fig 10. The screen seen by the user when the VR machine tool simulates the machine tool.

This demonstrated VR machine tool has the following functions: machine tool axis motion, tool change, reference position return, coolant spray, collision detection and $\mathrm{NC}$ decoding for controlling the machine. At the time of the exhibition, young engineers or students were much impressed by the interoperable VR machine tool. They learned how to use VR-based the 
system via hands-on experiences. However, it might be difficult for the elderly to adapt to the VR scene because of eyesight issues such as Presbyopia and Astigmatism. Overall, the integration of virtual reality and machine tools has been successfully accepted and experienced at an international fairs.

In addition to the establishment of the huge millturn machine tool VR-based demonstration system, a virtual laser-assisted milling machine motion simulation system is also under development. Figure 11 is a screen snapshot showing the machine tool definition. Figure 12 shows the presentation of the machine tool in the VR demonstration system. The axes of this laser-assisted milling machine are completely different from the huge mill-turn machine. It has been proven that different configurations of the machine tool can also be successfully constructed by using the VR technology.

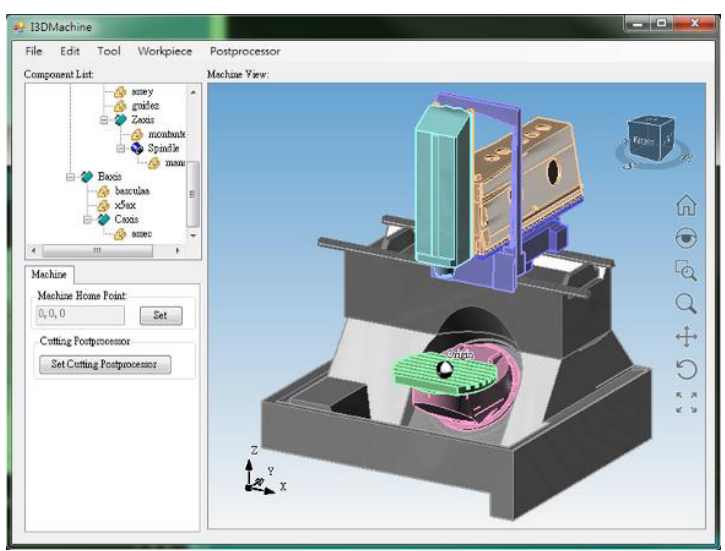

Fig 11. Virtual laser-assisted milling machine.

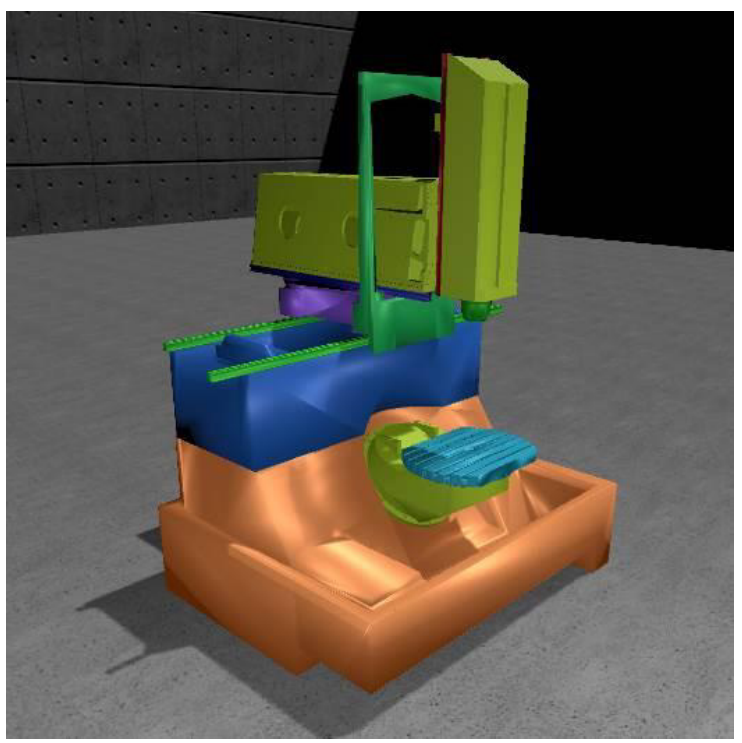

Fig 12. VR-based laser-assisted milling machine.

\section{Conclusion and future work}

One of the developed VR CNC machine tool is a large and heavy mill-turn machine. A head-mounted display (HMD) has been successfully attached to the developed VR CNC machine tool for the immersion viewing. From the results, it demonstrated that a user can see around the $3 \mathrm{D}$ scene of the huge mill-turn machine and the operation of the virtual CNC machine can be actuated by bare hand. The coolant display and collision detection functions had demonstrated the realistic operations for reminding the operator. The development of VR machine tool with laser-assisted milling has also been successfully under development. It showed the expandability of the proposed VR based technology for complicated processes and machine movement. In addition to the machine tool motion simulation, VR technology can also be used in the visualization of machining process in the future. It has also been successfully conducted to show the expandability of the VR-based technology for different applications.

One can conclude that VR will be adopted and paid more and more attention in the future in helping $\mathrm{CNC}$ machine tool promotion. Further study could be extended to the develpment of $\mathrm{CNC}$ education and training system, and also to the remote maintenance system for a complicated machine tools, too.

\section{Acknowledgment}

The authors appreciate the grant supported by the Metal Industry Research and Development Centre.

\section{References}

1. Ahmed Amer, Phillip Peralez, "Affordable altered perspectives: Making augmented and virtual reality technology accessible", IEEE Global Humanitarian Technology Conference (GHTC), 603-608 (2014)

2. David J. Zielinski, Ryan P. McMahan, Solaiman Shokur, Edgard Morya, Regis Kopper, "Enabling closed-source applications for virtual reality via OpenGL intercept-based techniques", IEEE 7th Workshop on Software Engineering and Architectures for Realtime Interactive Systems (SEARIS), 59-64 (2014)

3. Jiri Kovar, Katerina Mouralova, Filip Ksica, Jiri Kroupa, Ondrej Andrs , Zdenek Hadas, "Virtual Reality in Context of Industry 4.0 Proposed Projects at Brno University of Technology", 17th International Conference on Mechatronics Mechatronika (ME), 1-7 (2016)

4. Feng Tian, Pan Wang, ChunYan Dong, Jie Gao, Haifeng Tang, Li Qian, Haojun Xu, "3D Design Tools for Equipment Manufacturing and Exhibition Based on Internet", International Conference on 
Audio, Language and Image Processing (ICALIP), (2016)

http://ieeexplore.ieee.org/document/7846539/

5. Luigi Pelliccia, Philipp Klimant, Marco Schumann, Franziska Pürzel, Volker Wittstock, Matthias Putz, "Energy visualization techniques for machine tools in virtual reality", Procedia CIRP, 41, 329-333 (2016)

6. R. Neugebauer, P. Klimant, M. Witt, "Realistic Machine Simulation with Virtual Reality", Procedia CIRP, 3 , 103 - 108 ( 2012 )

7. Wu Man, Zhang Qun, "The Deconstruction and Reshaping of Space: the Application of Virtual Reality in Living Space", 9th International Conference on Measuring Technology and Mechatronics Automation (ICMTMA), 410-413 (2017)

8. Windo Hutabarat, John Oyekan, Christopher Turner, Ashutosh Tiwari, Neha Prajapat, Xiao-Peng Gan, Anthony Waller, "Combining virtual reality enabled simulation with 3D scanning technologies towards smart manufacturing", Winter Simulation Conference (WSC), 2774-2785 (2016)

9. Ahmed R. J. Almusawi, L. Canan Dülger, Sadettin Kapucu, "Robotic arm dynamic and simulation with Virtual Reality Model (VRM)", International Conference on Control, Decision and Information Technologies (CoDIT), 335-340 (2016)

10. Wolfgang Hürst, Bibi de Boer, Wouter Florijn, Xhi Jia Tan, "Creating new museum experiences for virtual reality", IEEE International Conference on Multimedia \& Expo Workshops (ICMEW), 1-6 (2016)

11. Nedel L, de Souza VC, Menin A, Sebben L, Oliveira J, Faria F, Maciel A, "Using Immersive Virtual Reality to Reduce Work Accidents in Developing Countries.", IEEE Computer Graphics and Applications, 36, issus:2, 36-46 (2016)

12.Catherine Ball, Kyle Johnsen, "An Accessible Platform for Everyday Educational Virtual Reality", IEEE 2nd Workshop on Everyday Virtual Reality(WEVR), 26-31 (2016)

13.Koreen Pagano, Angela Haddad, Tai Crosby "Virtual Reality-Making Good on the Promise of Immersive Learning: The effectiveness of in-person training, with the logistical and cost-effective benefits of computerbased systems", IEEE Consumer Electronics Magazine, 6, issue:1, 45-47 (2017)

14.Irina Makarova, Rifat Khabibullin, Eduard Belyaev, Angelina Bogateeva, "The application of virtual reality technologies in engineering education for the automotive industry", International Conference on Interactive Collaborative Learning (ICL), 536-544 (2015)

15. M. Travassos Valdez, C. Machado Ferreira, Maria João M. Martins, F. P. Maciel Barbosa, “3D virtual reality experiments to promote electrical engineering education", International Conference on Information Technology Based Higher Education and Training (ITHET), 1-4 (2015) 